\title{
Synthesis of Ethylenic and Acetylenic Triorganotins with Bulky Organic Ligands
}

\author{
V. Dodero, L.C. Koll and J.C. Podestá \\ Instituto de Investigaciones en Química Orgánica, Departamento de Química e Ing.Qca., Universidad \\ Nacional del Sur, Av. Alem 1253, 8000 Bahía Blanca, Argentina \\ E-mail: jpodesta@criba.edu.ar
}

\begin{abstract}
The syntheses of trineophyl- (1a) and tri-(-)-menthylstannyl phenylacetylene (1b) as well as that of (E)-1-trineophylestannyl-2-phenylethene (2) and (E)-1-trineophylstannyl1,2-diphenylethene (3) are described. The hydrostannation of $\mathbf{1 a}$ with an excess of trimethyltin hydride led to 1,1,1-tris(trimethyltin)-2-phenylethane (4) and/or 1,1-bis(trimethyltin)2-phenylethene (5) depending on the reaction conditions.
\end{abstract}

Keywords: tin hydride, vinylstannanes, addition, stereoselectivity, substitution.

\section{Introduction}

In previous studies carried out with trineophyltin hydride we have found that the size of the organic ligands attached to the tin atom affects not only the reactivity but also the stereoselectivity of the reactions of this hydride [1]. In order to study the effect of the size of the organic ligands on the stereochemistry of the hydrostannation, trineophyltin hydride was added to acetylenic systems under radical conditions. It was also started a study on the synthesis of organotin compounds with more than one triorganotin moiety, via the addition of trimethyltin hydride to trineophylstannyl phenylacetylene (1a).

\section{Experimental}

Compounds of type 1 were obtained with an average yield of $60 \%$ by modification of known techniques [2]. The hydrostannation reactions were carried out under free radical conditions as shown in the Scheme.

\section{Results and Discussion}

The obtained results are summarized in the following Scheme. The radical addition (Eq. 2) of trineophyltin hydride to both phenyl- and diphenylacetylene leads stereoselectively to the E isomers. 


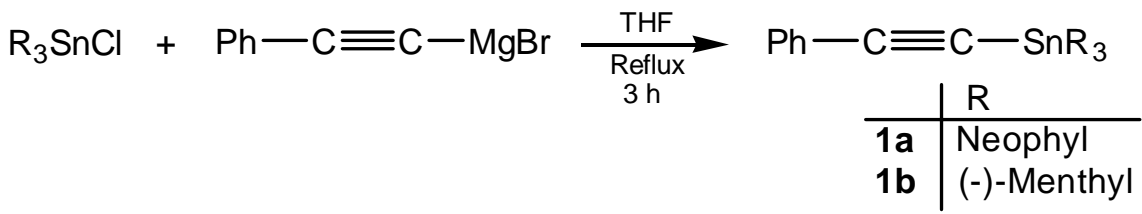

$$
\begin{aligned}
& \mathrm{Nph}_{3} \mathrm{SnH}+\mathrm{Ph}-\mathrm{C} \equiv \mathrm{C}-\mathrm{R} \underset{\begin{array}{c}
80^{\circ} \mathrm{C} \\
1 \mathrm{~h}
\end{array}}{\stackrel{\text { AlBN }}{\longrightarrow}} \\
& \text { Nph = Neophyil } \\
& \overbrace{\mathrm{SnNph}}{ }_{\mathrm{H}}^{\mathrm{Ph}} \\
& \begin{array}{l|l} 
& \multicolumn{1}{|c}{\mathrm{R}} \\
\hline \mathbf{2} & \mathrm{H}(99 \%) \\
\mathbf{3} & \mathrm{Ph}(80 \%)
\end{array}
\end{aligned}
$$

Whereas the addition of trimethyltin hydride to $\mathbf{1 a}$ in a ratio hydride $\mathbf{1} \mathbf{a}=5 / 1$ gave a mixture of compound $4(65 \%)$ and trineophyltin hydride, using a ratio hydride/1a $=4 / 1$ a mixture of trineophyltin hydride and compounds 4 (73\%) and 5 (27\%) was obtained. This strongly suggests that the first step in these reactions might be the substitution of the trineophyltin moiety by the trimethyltin group followed by the addition of the trimethyltin hydride.

Acknowledgements: This work was supported by CONICET (Buenos Aires), CIC (Provincia de Buenos Aires) and Universidad Nacional del Sur (Bahía Blanca, Argentina).

\section{References and Notes}

1. Podestá, J.C.; Chopa, A.B.; Giagante, N.N.; Zúñiga, A.E. Preparation and some Reactions of Neophyltin Anions. J. Organomet. Chem. 1995, 494, 5-10, and references cited therein.

2. Lequan, M.; Cadiot, P.; Composés Acétyléniques de l'Etain. Bull. Soc. Chim. Fr. 1965, 35-44. 